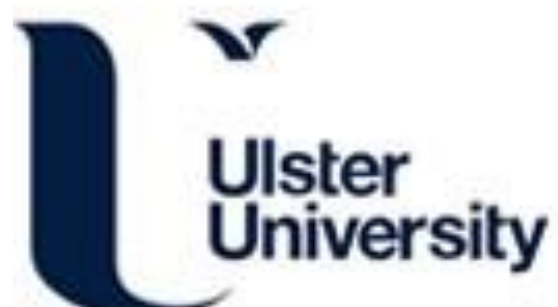

\section{Investigating the Neural Correlates of Pathological Cortical Networks in Alzheimer's Disease Using Heterogeneous Neuronal Models}

Abuhassan, K., Coyle, D., \& Maguire, LP. (2012). Investigating the Neural Correlates of Pathological Cortical Networks in Alzheimer's Disease Using Heterogeneous Neuronal Models. IEEE Transactions on Biomedical Engineering, 59(3), 890-896. https://doi.org/10.1109/TBME.2011.2181843

Link to publication record in Ulster University Research Portal

Published in:

IEEE Transactions on Biomedical Engineering

Publication Status:

Published (in print/issue): 01/03/2012

DOI:

10.1109/TBME.2011.2181843

\section{Document Version}

Publisher's PDF, also known as Version of record

\section{General rights}

Copyright for the publications made accessible via Ulster University's Research Portal is retained by the author(s) and / or other copyright owners and it is a condition of accessing these publications that users recognise and abide by the legal requirements associated with these rights.

\section{Take down policy}

The Research Portal is Ulster University's institutional repository that provides access to Ulster's research outputs. Every effort has been made to ensure that content in the Research Portal does not infringe any person's rights, or applicable UK laws. If you discover content in the Research Portal that you believe breaches copyright or violates any law, please contact pure-support@ulster.ac.uk. 


\title{
Investigating the Neural Correlates of Pathological Cortical Networks in Alzheimer's Disease Using Heterogeneous Neuronal Models
}

\author{
Kamal Abuhassan*, Damien Coyle, Member, IEEE, and Liam P. Maguire
}

\begin{abstract}
This paper describes an investigation into the pathophysiological causes of abnormal cortical oscillations in Alzheimer's disease (AD) using two heterogeneous neuronal network models. The effect of excitatory circuit disruption on the beta band power $(13-30 \mathrm{~Hz})$ using a conductance-based network model of 200 neurons is assessed. Then, the neural correlates of abnormal cortical oscillations in different frequency bands based on a larger network model of $\mathbf{1 0 0 0}$ neurons consisting of different types of cortical neurons are also analyzed. EEG studies in AD patients have shown that beta band power $(13-30 \mathrm{~Hz})$ decreased in the early stages of the disease with a parallel increase in theta band power $(4-7 \mathrm{~Hz})$. This abnormal change progresses with the later stages of the disease but with decreased power spectra in other fast frequency bands plus an increase in delta band power $(1-3 \mathrm{~Hz})$. Our results show that, despite the heterogeneity of the network models, the beta band power is significantly affected by excitatory neural and synaptic loss. Second, the results of modeling a functional impairment in the excitatory circuit shows that beta band power exhibits the most decrease compared with other bands. Previous biological experiments on different types of cultural excitatory neurons show that cortical neuronal death is mediated by dysfunctional ionic behavior that might specifically contribute to the pathogenesis of $\beta$-amyloid-peptide-induced neuronal death in AD. Our study also shows that beta band power was the first affected component when the modeled excitatory circuit begins to lose neurons and synapses.
\end{abstract}

Index Terms-Alzheimer's disease (AD), computational models, EEG, functional deficits, structural impairment.

\section{INTRODUCTION}

A LZHEIMER's disease (AD) is the most common neurodegenerative disorder associated with progressive dementia. The clinical symptoms of AD are cognitive and intellectual deficits, and behavior dysfunction. In most instances, symptoms develop gradually or precipitously. AD constitutes approximately $70 \%$ of all dementia cases and is expected to affect 1 in 85 people worldwide by 2050 [1]. It has a signifi-

Manuscript received July 22, 2011; accepted November 27, 2011. Date of publication December 26, 2011; date of current version February 17, 2012. This work is supported by the Northern Ireland Department for Education and Learning under the Strengthening the All Island Research Base programme. Asterisk indicates corresponding author.

${ }^{*} \mathrm{~K}$. Abuhassan is with the Intelligent Systems Research Centre, University of Ulster, Derry BT48 7JL, U.K. (e-mail: Abuhassan-k@email.ulster.ac.uk).

D. Coyle and L. P. Maguire are with the School of Computing and Intelligent Systems and the Intelligent Systems Research Centre, University of Ulster, Derry BT48 7JL, U.K. (e-mail: dh.coyle@ulster.ac.uk; lp.maguire@ulster.ac.uk).

Digital Object Identifier 10.1109/TBME.2011.2181843 cant impact on patients and caregivers, and generates substantial costs on health care providers in developed countries [2]. Clearly understanding the dynamics of neuronal networks in healthy and dysfunctional cortices is important and could aid in the development of effective diagnostic tools and prevention measures.

For the last few decades, EEG has been utilized for diagnosing dementias. EEG is a measure of the electrical activity along the scalp produced by a sufficiently large population of neurons. There is a strong correlation between cognitive deficit and the degree of the EEG abnormality. EEG spectral analysis in $\mathrm{AD}$ patients has shown a decrease in the mean frequency, alpha $(8-12 \mathrm{~Hz})$ and beta $(13-30 \mathrm{~Hz})$ band powers with a parallel increase in delta $(1-3 \mathrm{~Hz})$ and theta $(4-7 \mathrm{~Hz})$ band powers compared with those of healthy elderly subjects [3]. The attenuation of alpha band power is associated with an increase in lower alpha $(8-10 \mathrm{~Hz})$ band power and a parallel decrease in upper alpha (10-12 Hz) band power [4].

The EEG abnormalities in AD indicate functional and anatomical impairment of the cerebral cortex affected by the disease. More investigations are needed to provide insights to the underlying neurological basis of those abnormalities as well as to couple those findings with the severity of the disease. This study is targeted at investigating the relationship between $\mathrm{AD}$ EEG abnormalities and some neuropathological changes during $\mathrm{AD}$ using a conductance-based local neuronal network oscillating in beta band [5] and a simple larger network model of different types of cortical neurons that oscillates in different frequency bands [6].

The neuropathology of AD is characterized by an enormous neuronal and synaptic loss in the cerebral cortex and certain subcortical regions, and the formation of both neurofibrillary tangles (NFT) and neurotic plaques (NP) [7]. NFT are pathological tangles of hyperphosphorylated tau protein accumulated in the brains of $\mathrm{AD}$ patients; it is believed that the number of NFT is directly correlated with neuronal dysfunction as well as indicating the degree of dementia [8]. $\beta$-amyloid peptide $(\mathrm{A} \beta)$ is the main component of NP observed in the brains of patients with $\mathrm{AD}$ and has been suggested to contribute to the pathogenesis of neuronal degeneration [9].

A number of studies reported a deregulation of neuronal $\mathrm{K}+$ channel function after exposure to $\mathrm{A} \beta$ peptide fragments, which led to remarkable perturbations in neuronal behavior [10]- [12]. These channels provide a negative feedback to the membrane potential of neurons. Thus, it regulates the neuronal dynamics including the timing of interspike intervals (time between 
spikes), setting the resting potential, and keeping action potentials short [13]. Therapeutic suggestions can be derived from computational models of dysfunctional neural behavior to slow down neural degeneration in AD.

The goal of this study is to elaborate and extend the findings in [14] and [15]. A recent modeling study of the hippocampal CA1 and medial septal regions has proposed that hippocampal theta band power is increased as a result of $\mathrm{A} \beta$-induced reduction in A-type potassium current $I_{A}$ in $e$-cells [16]. This suggests the differential vulnerability of neurons and synapses in different cortical and subcortical areas to $\mathrm{A} \beta$ fragments.

In this study, we examine the effects of neuronal/synaptic loss and deregulation of negative feedback to the membrane potential of cortical neurons (which mainly results from $\mathrm{A} \beta$ induced dysfunctional $\mathrm{K}+$ channels) on the oscillatory activity of cortical networks.

Firstly, the effect of excitatory circuit disruption on beta band power $(13-30 \mathrm{~Hz})$ is investigated using a local network model. Then, the investigation is extended to explore the underlying neurological sources of abnormal dynamics in different frequency bands based on a larger network model consisting of different types of cortical neurons.

The paper is outlined as follows. The network models are described in Section II. The results and analysis are provided in Section III. Finally, discussions and conclusion are presented in Sections IV and V, respectively.

\section{NETWORK MODELS}

\section{A. Local Neuronal Network}

We simulated a conductance-based neuronal network of 200 cells containing 160 excitatory ( $e$-cells) and 40 inhibitory ( $i$-cells) neurons in the baseline (normal) case. The ratio of $e$ - to $i$-cells is $4(80 \%)$ to $1(20 \%)$ motivated by the anatomy of the mammalian cortex [17]. The cells are connected all-to-all assuming that $(e-e)$ synapses are weak within local networks [18]. Parameters and functional forms of the equations are adopted from [5].

Neurons were modeled by Hodgkin-Huxley dynamics; $i$-cells were of the form

$$
\begin{aligned}
C\left(\frac{d V_{i}}{d t}\right)= & -g_{L}\left(V_{i}-V_{L}\right)-g_{K} n^{4}\left(V_{1}-V_{K}\right) \\
& -g_{\mathrm{Na}} m^{3} h\left(V_{i}-V_{\mathrm{Na}}\right)-I_{\mathrm{syn}, i}+I_{0}
\end{aligned}
$$

and the $e$-cells were modeled by the equations

$$
\begin{aligned}
C\left(\frac{d V_{e}}{d t}\right)= & -g_{L}\left(V_{e}-V_{L}\right)-g_{K} n^{4}\left(V_{e}-V_{K}\right) \\
& -g_{\mathrm{Na}} m^{3} h\left(V_{e}-V_{\mathrm{Na}}\right)-g_{\mathrm{AHP}} w\left(V_{e}-V_{K}\right) \\
& -I_{\mathrm{syn}, e}+I_{0} .
\end{aligned}
$$

Both types of cells have a leak $(L)$, transient sodium $(\mathrm{Na})$, and delayed rectifier potassium $(\mathrm{K})$ current. The $e$-cells have an additional after-depolarizing potential (AHP) resulting in a slow outward potassium current.
The maximal conductances were $g_{\mathrm{Na}}=100 \mathrm{mS} / \mathrm{cm}^{2}$, $g_{K}=80 \mathrm{mS} / \mathrm{cm}^{2}, g_{L}=0.1 \mathrm{mS} / \mathrm{cm}^{2}$, and $g_{\mathrm{AHP}}=0.3 \mathrm{mS} / \mathrm{cm}^{2}$. Reversal potentials were $V_{L}=-67 \mathrm{mV}, V_{K}=-100 \mathrm{mV}$, and $V_{\mathrm{Na}}=50 \mathrm{mV}$. The capacitances for $e$ - and $i$-cells were $1 \mathrm{AF} / \mathrm{cm}^{2}$. Parameters for both the $e$ - and $i$-cells were the same; the only differences are in the synaptic currents and the driving currents, $I_{0}$. The gating variables $m, h, n$ satisfy equations of the form

$$
\frac{d x}{d t}=a_{x}(V)(1-x)-b_{x}(V)(x) .
$$

For $x=m, h, n$ where

$$
\begin{aligned}
& a_{m}(V)=\frac{0.32(54+V)}{(1-\exp ([-(V+54) / 4]))} \\
& b_{m}(V)=\frac{0.28(V+27)}{(\exp ([(V+27) / 5])-1)} \\
& a_{h}(V)=0.128 \exp \left[\frac{-(V+50)}{18}\right] \\
& b_{h}(V)=\frac{0.032(V+52)}{(1+\exp ([-(V+27) / 5]))} \\
& a_{n}(V)=\frac{4+52) / 5]))}{(1-\exp ([-(V+5)} \\
& b_{n}(V)=0.5 \exp \left[\frac{-(57+V)}{40}\right) .
\end{aligned}
$$

The gating variable $w$ is represented by

$$
\begin{aligned}
\frac{d w}{d t} & =\frac{\left(w_{\infty}(V)-w\right)}{\tau_{w}(V)} \\
w_{\infty}(V) & =\frac{1}{(1+\exp ([-(V+35) / 10]))} \\
\tau_{w}(V) & =\frac{400}{(3.3 \exp ([(V+35) / 20])+\exp ([-(V+35) / 20]))} .
\end{aligned}
$$

Synaptic currents were modeled as follows:

$$
I_{\mathrm{syn}, \alpha}=g_{i \alpha} s_{i, \mathrm{tot}}\left(V_{\alpha}-V_{\mathrm{in}}\right)+g_{e \alpha} s_{e, \mathrm{tot}}\left(V_{\alpha}-V_{\mathrm{ex}}\right)
$$

for $\alpha=\{e, i\}$.

Reversal potentials for AMPA and $\mathrm{GABA}_{\mathrm{A}}$ were $V_{\mathrm{ex}}=0 \mathrm{mV}$ and $V_{\text {in }}=-80 \mathrm{mV}$, respectively. The synaptic gates satisfy:

$$
\begin{aligned}
s_{\alpha, \text { tot }} & =\frac{1}{N_{\propto}} \sum_{\alpha-\text { cells }} s_{\propto} \\
\frac{d s_{\alpha}}{d t} & =a_{\alpha}\left(1+\tanh \left(\frac{V_{\alpha}}{4}\right)\right)\left(1-s_{\alpha}\right)-\left(\frac{s_{\alpha}}{\tau_{\alpha}}\right)
\end{aligned}
$$

where $a_{e}=20 / \mathrm{ms}, a_{i}=1 / \mathrm{ms}, \tau_{e}=2.4 \mathrm{~ms}$, and $\tau_{i}=12 \mathrm{~ms}$. The inhibitory GABA $\mathrm{A}_{\mathrm{A}}$ conductances, $g_{i e}$ and $g_{i i}$ are $5 \mathrm{mS} / \mathrm{cm}^{2}$ and $10 \mathrm{mS} / \mathrm{cm}^{2}$, respectively.

The excitatory conductances were $g_{e e}=0.01 \mathrm{mS} / \mathrm{cm}^{2}$ and $g_{e i}=0.05 \mathrm{mS} / \mathrm{cm}^{2}$. The model time was $2000 \mathrm{~ms}$ and spike trains were assessed after $1000 \mathrm{~ms}$ allowing a settlement period of $1000 \mathrm{~ms}$. Gaussian noise generated by a wiener process was 


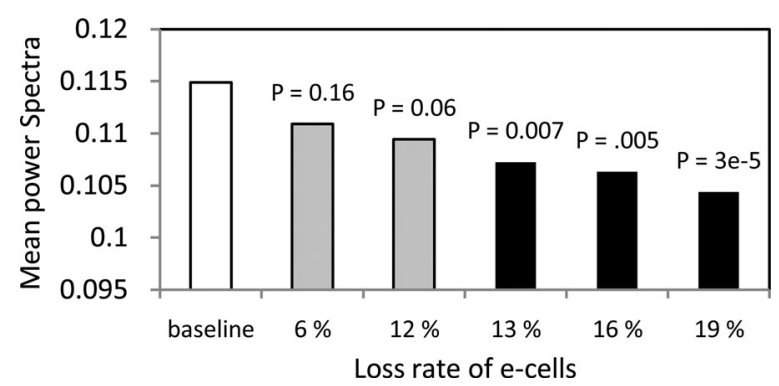

Fig. 2. Mean beta band power (13-30 Hz) for a physiological case (baseline) and cases with reduced $e$-cells. Differences ( $P$ values) measured by ANOVA are presented in the figure. Black bars correspond to significant differences. The number of trials is 25 for each setup.

with random input, therefore, representing 10 individuals; the healthy control group. The model parameters are then modified to test each hypothesis. Again the model is run 10 times for each test, with each test representing a group with a certain neuropathology.

The FFT tool has been applied on the spiking train produced by each model to calculate the power spectra within the following frequency bands: delta $(1-3 \mathrm{~Hz})$, theta $(4-7 \mathrm{~Hz})$, alpha $(8-$ $12 \mathrm{~Hz})$, beta1 $(13-18 \mathrm{~Hz})$, beta2 $(19-21 \mathrm{~Hz})$, beta3 $(22-30 \mathrm{~Hz})$, gamma $(30-50 \mathrm{~Hz})$, and full $(1-70 \mathrm{~Hz})$ bands; the categorization for the frequency bands is based on [19].

One-way repeated measures ANOVA has been used to analyze statistical significance of the difference in band power within each frequency band across the different groups, as outlined previously, $P$ values smaller than 0.05 were considered statistically significant.

\section{RESULTS}

A. Decrease in Beta Band Power Induced by Loss of Excitatory Neurons and Synapses in the Local Network Model

A significant decrease in beta band power was observed after the excitatory circuit looses more than $20 e$-cells (number of $e$-cells becomes $\leq 139$, loss rate $\geq 13 \%, P<0.05$ ), as illustrated in Fig. 2.

We refer to this point as a breakdown point since the power spectra of beta rhythm exhibits a significant decrease after this point. In the network model, the death of each $e$-cell is associated with a synaptic loss of 319 excitatory synapses (1\% loss of excitatory synapses) since the network is fully connected (each $e$-cell receives 159 e-synapses, innervates $159 e$-cells, and has one recurrent synapse with itself).

The same response point appears after varying the network setup as follows: settlement period is increased to $2 \mathrm{~s}$ and power spectra differences are assessed based on the spike trains collected after second 2 until second 4 . Thus, model time is $4 \mathrm{~s}$.

\section{B. Effects of Varying the Number of Excitatory Neurons on the Oscillatory Activity of the Larger Network Model}

In case study 1 , the power spectrum averages of alpha and beta3 bands are significantly decreased when decreasing the number of $e$-cells $\left(N_{e}\right)$ from 794 to 764 (loss\% of $e$-cells is
TABLE II

MeAn PoWer SPECTRA IN CASE StUdy 1

\begin{tabular}{cccc}
\hline \hline $\begin{array}{c}\text { Frequency } \\
\text { band }\end{array}$ & $\begin{array}{c}\text { Min. } \\
\text { value }\end{array}$ & $\begin{array}{c}\text { Control } \\
\text { value }\end{array}$ & $\begin{array}{c}\text { Decrease } \\
\text { percentage }\end{array}$ \\
\hline Delta & 3.498 & 3.737 & $6.4 \%$ \\
Theta & 2.71 & 3.104 & $12.7 \%$ \\
Alpha & 3.178 & 4.236 & $25 \%$ \\
Beta3 & 6.125 & 7.326 & $16.4 \%$ \\
Gamma & 13.15 & 15.034 & $12.5 \%$ \\
Full & 44.25 & 50.306 & $12 \%$ \\
\hline \hline
\end{tabular}

increased from $0.75 \%$ to $4.5 \%$ ). It is expected that reducing $N_{e}$ increases the amount of inhibition in the network and slows down the spiking activity, which explains the significant changes in the full band. From Table II, we can see that delta (slow rhythm) was not significantly affected, in contrast to the higher frequency bands.

Decrease percentage is calculated according to the following formula:

$$
\text { Decrease } \%=\left(\frac{([\text { Control value }]-[\text { Minimum value }]}{[\text { Control value }]}\right) 100 \% \text {. }
$$

The minimum mean value was calculated by comparing the mean value of the power spectrum in the corresponding frequency band across all groups (each group contains 10 trials) in case study 1 . We speculate that the power spectrum is shifted to lower frequencies with a parallel decrease in the coherence of fast rhythms, see Fig. 3(a). The statistical analyses show that the significant decrease started in beta3 band power $\left(N_{e}=782\right.$, $2.25 \%$ loss in $e$-cells).

This observation can be further explained by inspecting the minimum values of the power spectrum averages for slower and faster frequency bands, as given in Table II. The mean values of power spectrum for alpha and delta frequency band power for the groups in case study 1 are also presented in Fig. 3(b) and (c), respectively. The analyses show that the power spectrum in delta, theta, beta1, and beta 2 bands was not significantly decreased.

\section{Effects of Varying Parameter b for e-Cells on the Oscillatory Activity of the Larger Network Model}

The datasets in case study 2 contained important information about the magnitude of mean power ranges in high frequency bands. As presented in Table III, there are higher shifts from alpha, beta1, beta2, and beta 3 band powers than slower frequency bands similar to previous observations for case study 1 outlined previously. The beta2 band is the most affected one. Again, decreasing parameter $b$ (17) for $e$-cells upregulates the negative feedback $u$ to the membrane potential $V(16)$, which results in high-threshold spiking dynamics and decreases the spiking activity of $e$-cells. This accounts for the activation of $\mathrm{K}^{+}$ionic currents and inactivation of $\mathrm{Na}^{+}$ionic currents [6].

Values of parameter $b$ (17) for $e$-cells were decreased from 0.1995 (group 1) to 0.195 (group 10). The length of decreasing 


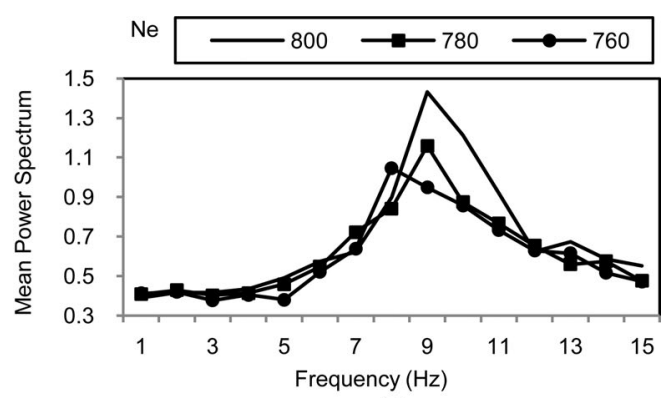

(a)

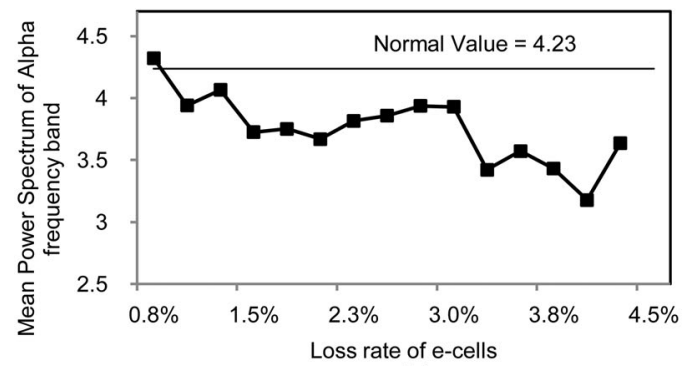

(b)

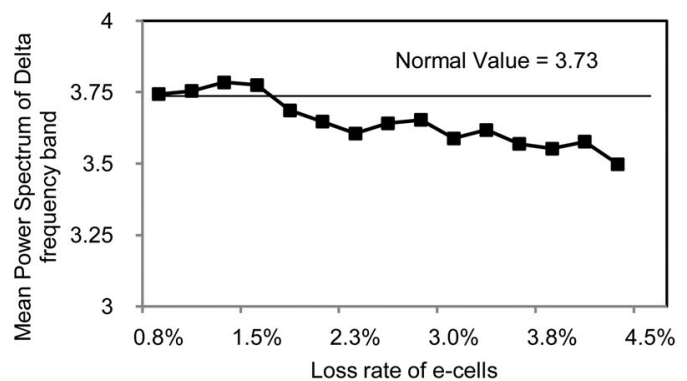

(c)

Fig. 3. Effects of increasing the loss rate of $e$-cells on the mean power spectrum. (a) Power spectrum is shifted to lower frequencies as more $e$-cells loss occurs. (b) and (c) Tracking the changes in alpha and delta band powers, respectively, as the number of $e$-cells is gradually decreased. The normal value (when $N_{e}=800$ and the ratio of $e$ - to $i$-cells is 4 to 1 ) of the mean power spectrum for delta and alpha frequency bands (control group) is indicated by a horizontal line.

step for $b(17)$ between the groups in case study 2 is 0.0005 , i.e., value of parameter $b$ for the second group is 0.199 . Control (normal) value of parameter $b(17)$ for $e$-cells is 0.2 . The total number of groups in case study 2 is $11([(0.1995-0.195) / 0.0005]+1$ + control group). The number of trials is 10 for each setup.

In Fig. 4, we demonstrate the simulated EEG signal for three groups with different values of parameter $b$.

\section{DISCUSSION}

\section{A. Structural Changes}

It is commonly thought that an increase in theta band activity appears in the early stages of $\mathrm{AD}$ with a parallel decrease in beta activity; delta activity increases later during the course of the disease [3]. However, the underlying neural causes of abnormal EEG dynamics in AD are still poorly understood.

This research is concerned with developing a better understanding of the pathophysiological causes of abnormal cortical oscillations in $\mathrm{AD}$ based on a computational modeling approach.
TABLE III

MEAn Power SPectra AfTer VARYing PARAmeter $b$ for $e$-CELls (CASE STUdy 2)

\begin{tabular}{cccc}
\hline \hline $\begin{array}{c}\text { Frequency } \\
\text { band }\end{array}$ & $\begin{array}{c}\text { Min. } \\
\text { value }\end{array}$ & $\begin{array}{c}\text { Control } \\
\text { value }\end{array}$ & $\begin{array}{c}\text { Decrease } \\
\text { percentage }\end{array}$ \\
\hline Delta & 3.208 & 3.737 & $14.2 \%$ \\
Theta & 2.544 & 3.104 & $18 \%$ \\
Alpha & 2.937 & 4.236 & $30.7 \%$ \\
Beta1 & 2.671 & 3.579 & $25.4 \%$ \\
Beta2 & 1.105 & 1.787 & $38.7 \%$ \\
Beta3 & 5.359 & 7.326 & $26.9 \%$ \\
Gamma & 11.557 & 15.034 & $23.1 \%$ \\
Full & 39.326 & 50.306 & $21.8 \%$ \\
\hline \hline \\
Minimum and control (physiological) values of the power \\
spectra averages for slower and faster frequency bands in case \\
study 2.
\end{tabular}

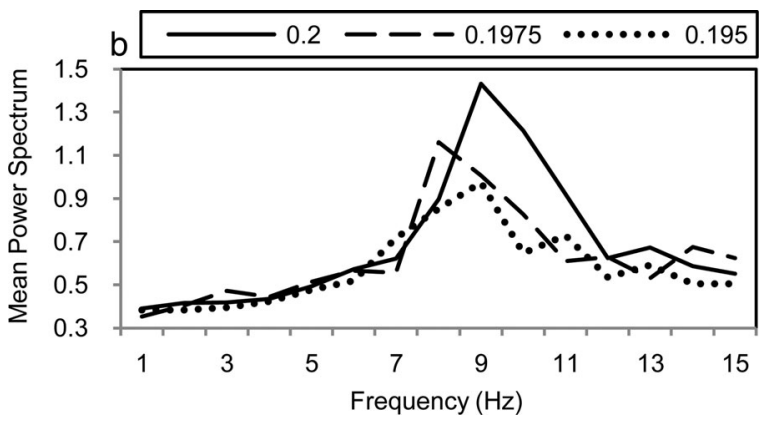

Fig. 4. Effect of decreasing parameter $b$ for $e$-cells on the mean power spectrum.

In the current study, the effect of excitatory neural and synaptic loss on beta band power has been evaluated with two network models (along with other rhythms using the larger network model). Despite the heterogeneity of the network models, we show that the power spectrum of beta rhythm is significantly affected by excitatory neural and synaptic loss. In case study 1 (the large network model), we find that the significant decrease begins in the beta 3 band (upper beta) when $N_{e}$ was $782(2.25 \%$ loss in $e$-cells).

The sequence of gradual changes in faster bands is compatible with EEG studies [3]. Although the mean power spectrum of the full band is significantly decreased, slow bands (delta and theta) are only slightly affected by the decrease and most of the signal power was shifted from fast bands toward slow bands.

The decreased activity in alpha, beta, and gamma waves is related to changes in excitatory circuit activity [20]. The study involved the analysis of a large EEG dataset using global field synchronization (GFS), a novel measure to quantify global EEG synchronization [20]. A high GFS index for a certain frequency band reflects increased functional connectivity between brain processes. The patient's results showed increased GFS values in the delta band, and decreased GFS values in alpha, beta, and gamma frequency bands, supporting the disconnection syndrome hypothesis [20] and [21].

Other AD studies have reported decreased synchronization of alpha band in the early stages of $\mathrm{AD}$ [22]. In a previous study [4], we utilized a classical computational model of alpha rhythm proposed by [23] to explore the relationship between synaptic activities in a thalamocortical circuitry and diminished 


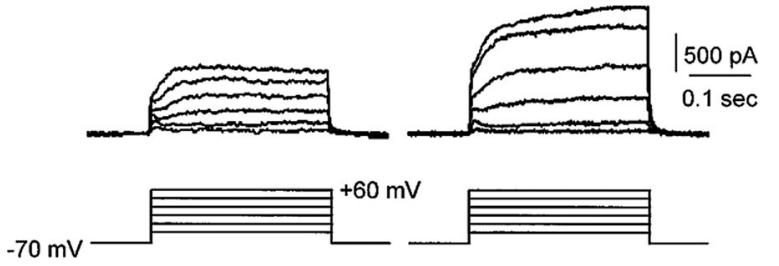

Control

$A \beta 25-35$

Fig. 5. Upregulation of $I_{K}$ by $\beta$-amyloid 25-35 in cortical $e$-cells [24]. (Reproduced with permission from S.P. Yu.)

alpha power. In [4], it was found that the deterioration in excitatory synaptic pathways during AD biased the dynamics toward increased inhibitory activity and affected alpha rhythmic activity.

In this study, we first traced the changes in alpha band power after the structural impairments in the excitatory circuit (case study 1). We observe similar changes in alpha band power, as proposed in [4]; see Fig. 3(a). Then, we further explored the consequences of functional deficits in excitatory circuits (case study 2) on alpha band power, see Fig. 4.

According to the simulation results, we speculate that the functional deficits of ionic channels contribute to abnormal alpha band power in AD.

\section{B. Functional Changes}

It was demonstrated that cortical neuronal death is mediated by the enhancement of outward $\mathrm{K}+$ current and such enhancement might specifically contribute to the pathogenesis of $\mathrm{A} \beta$ induced neuronal death [24].

The results in [24] showed that $\mathrm{A} \beta$ fragment $1-42$ or $25-35$ exposure induce an upregulation in the delayed rectifier $\mathrm{K}+$ current $I_{K}$, an increase in maximal conductance, and a shift in its activation voltage relationship toward hyperpolarized levels, see Fig. 5.

Cortical neuronal cultures that contained cells from different layers of cortex were used in the experiments. The cells were excitatory because they responded to N-methyl D-aspartate (NMDA) or glutamate stimulation [24].

The upregulation of this type of $\mathrm{K}+$ currents provides a more negative feedback to the membrane potential of $e$-cells followed by neuronal death. We speculate that the neural mechanism that underlies the sequence of abnormal changes into EEG of AD can be described by inspecting the results in case study 2 , which showed a parallel significant decrease in different bands with a higher shift from upper frequency band powers, in particular, the power spectrum of beta 2 and alpha rhythms. The significant decrease within beta band power appears also (before other rhythms) when decreasing $N_{e}$, followed by a breakdown in other frequency bands when $N_{e}$ decreases more and more (increased rate of neuronal and synaptic death).

\section{CONCLUSION}

The impairment of excitatory circuitry appears to play an important role in abnormal oscillatory activity of the neuronal networks and this is supported by our study, which uses simple network models. Furthermore, the observation that the death of $e$-cells is preceded by dysfunctional behavior and changes in the ionic channels has been investigated in the study. The dynamical changes of the rhythmicity in the network as a result of alterations in the negative feedback for membrane potential in $e$-cells have been focused on. Future investigations will be based on a network consisting of 100000 cortical neurons, distribution of axonal conduction delays, long-term spike-timing-dependent synaptic plasticity, receptor kinetics, and short-term plasticity. The network structure will be informed by the organization of the cerebral cortex [25].

\section{REFERENCES}

[1] R. Brookmeyer, E. Johnson, K. Ziegler-Graham, and H. M. Arrighi, "Forecasting the global burden of Alzheimer's disease," Alzheimer's Dementia, vol. 3, pp. 186-191, 2007.

[2] C. W. Zhu and M. Sano, "Economic considerations in the management of Alzheimer's disease," Clin. Interventions Aging, vol. 1, pp. 143-154, 2006.

[3] J. Jeong, "EEG dynamics in patients with Alzheimer's disease," Clin. Neurophysiol., vol. 115, pp. 1490-1505, 2004.

[4] B. Sen, D. Coyle, and L. Maguire, "A thalamo-cortico-thalamic neural mass model to study alpha rhythms in Alzheimer's disease," Neural Netw. Special Issue Brain Disorders, vol. 24, pp. 631-645, 2011.

[5] O. Jensen, P. Goel, N. Kopell, M. Pohja, R. Hari, and B. Ermentrout, "On the human sensorimotor-cortex beta rhythm: Sources and modeling," NeuroImage, vol. 26, pp. 347-355, 2005.

[6] E. M. Izhikevich, "Simple model of spiking neurons," IEEE Trans. Neural Netw., vol. 14, no. 6, pp. 1569-1572, Nov. 2003.

[7] D. J. Selkoe, "Alzheimer's disease is a synaptic failure," Science, vol. 298 , pp. 789-791, 2002.

[8] J. P. Brion, "Neurofibrillary tangles and Alzheimer's disease," Eur. Neurol., vol. 40, pp. 130-140, 1998.

[9] J. A. Hardy and G. A. Higgins, "Alzheimer's disease: The amyloid cascade hypothesis," Science, vol. 256, pp. 184-185, 1992.

[10] A. Pannaccione, F. Boscia, A. Scorziello, A. Adornetto, P. Castaldo, R Sirabella, M. Taglialatela, G. F. Di Renzo, and L. Annunziato, "Upregulation and increased activity of KV3.4 channels and their accessory subunit MinK-related peptide 2 induced by amyloid peptide are involved in apoptotic neuronal death," Mol. Pharmacol., vol. 72, pp. 665-673, 2007.

[11] Y. Pan, X. Xu, X. Tong, and X. Wang, "Messenger RNA and protein expression analysis of voltage-gated potassium channels in the brain of Abeta(25-35)-treated rats," J. Neurosci. Res., vol. 77, pp. 94-99, 2004.

[12] L. D. Plant, N. J. Webster, J. P. Boyle, M. Ramsden, D. B. Freir, C. Peers, and H. A. Pearson, "Amyloid beta peptide as a physiological modulator of neuronal 'A'-type K+ current," Neurobiol.Aging, vol. 27, pp. 1673-1683, 2006.

[13] S. G. Birnbaum, A. W. Varga, L.-L. Yuan, A. E. Anderson, J. D. Sweatt, and L. A. Schrader, "Structure and function of Kv4-family transient potassium channels," Physio. Rev., vol. 84, pp. 803-833, 2004.

[14] K. Abuhassan, D. Coyle, and L. Maguire, "Simple spiking networks to investigate pathophysiological basis of abnormal cortical oscillations in Alzheimer's disease," Irish J. Med. Sci., vol. 180, suppl. 2, pp. 62, 2011.

[15] K. Abuhassan, D. Coyle, and L. Maguire, "Employing neuronal networks to investigate the pathophysiological basis of abnormal cortical oscillations in Alzheimer's disease," in Proc. 33rd Annu. IEEE Eng. Med. Biol. Soc. Conf., Boston, MA, 2011, pp. 2065-2068.

[16] X. Zou, D. Coyle, K. Wong-Lin, and L. Maguire, (2011, Jun.). Computational study of hippocampal-septal theta rhythm changes due to beta-amyloid-altered ionic channels, PloS ONE [Online], 6(6). Available: http://dx.plos.org/10.1371/journal.pone.0021579.

[17] V. Braitenberg and A. Schuz, Anatomy of the Cortex: Statistics and Geometry. Berlin, Germany: Springer Verlag, 1991. 
[18] S. R. Jones, D. J. Pinto, T. J. Kaper, and N. Kopell, "Alpha-frequency rhythms desynchronize over long cortical distances: A modeling study," J. Comput. Neurosci., vol. 9, pp. 271-291, 2000.

[19] Y.-M. Park, H.-J. Che, C.-H. Im, H.-T. Jung, S.-M. Bae, and S.-H. Lee, "Decreased EEG synchronization and its correlation with symptom severity in Alzheimer's disease," Neurosci. Res., vol. 62, pp. 112-117, 2008.

[20] T. Koenig, L. Prichep, T. Dierks, D. Hubl, L. O. Wahlund, E. R. John, and V. Jelic, "Decreased EEG synchronization in Alzheimer's disease and mild cognitive impairment," Neurobiol. Aging, vol. 26, pp. 165-171, 2005.

[21] X. Li, D. Coyle, L. Maguire, D. Watson, and T. McGinnity, "Grey matter concentration and effective connectivity changes in Alzheimer's disease: A longitudinal structural MRI study," Neuroradiology, vol. 53, pp. 733748, 2011

[22] J. L. Cantero, M. Atienza, A. Cruz-Vadell, A. Suarez-Gonzalez, and E. GilNeciga, "Increased synchronization and decreased neural complexity underlie thalamocortical oscillatory dynamics in mild cognitive impairment," NeuroImage, vol. 46, pp. 938-948, 2009.

[23] F. H. Lopes da Silva, A. Hoeks, H. Smits, and L. H. Zetterberg, "Model of brain rhythmic activity. The alpha-rhythm of the thalamus," Kybernetik, vol. 15 , pp. 27-37, 1974.

[24] S. P. Yu, Z. S. Farhangrazi, H. S. Ying, C. H. Yeh, and D. W. Choi, "Enhancement of outward potassium current may participate in beta-amyloid peptide-induced cortical neuronal death," Neurobiol.Dis., vol. 5, pp. 8188, 1998.

[25] E. Izhikevich, J. Gally, and G. Edelman, "Spike-timing dynamics of neuronal groups," Cereb. Cortex, vol. 14, pp. 933-944, 2004.

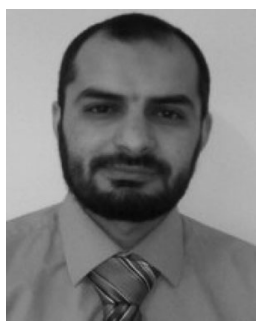

Kamal Abuhassan received a B.S. degree in computer science from Mu'tah University, Karak, Jordan, in 2002, and a M.S. degree in computer science from the University of Jordan, Amman, Jordan, in 2007. $\mathrm{He}$ is currently working toward the Ph.D. degree at the Intelligent Systems Research Centre, University of Ulster, Derry, U.K.

He has more than six years of experience in developing Service Oriented Architecture and J2EE applications using JAVA and IBM tools. He has been with Oracle and IBM partner companies in Jordan. He has Sun Certified Java Programmer, Sun Certified Java Web Components Developer, Sun Certified Web Services Developer, and IBM Web Content Management certifications. He is involved in developing models using MATLAB and $\mathrm{C}++$ with message passing interface. His main research interests include the investigation of abnormal brain oscillation's biomarkers in Alzheimer's disease with computational modeling of neuronal networks.

Mr. Abuhassan has a research paper published in the 33rd Annual IEEE Engineering in Medicine and Biology Society Conference, Boston, MA.

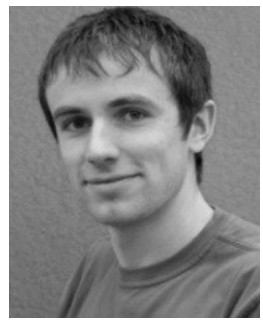

Damien Coyle (M'05) received a first class degree in computing and electronic engineering and the Ph.D. degree in intelligent systems engineering from the University of Ulster, Derry, U.K., in 2002 and 2006, respectively.

Since 2006, he has been a Lecturer at the School of Computing and Intelligent Systems, University of Ulster, where he is also a member of the Intelligent Systems Research Centre. His research interests include brain-computer interfaces, computational intelligence, computational neuroscience and biomedical signal processing and he has coauthored several journal articles and book chapters in these areas.

Dr. Coyle is the 2008 recipient of the IEEE Computational Intelligence Society's (CIS) Outstanding Doctoral Dissertation Award and the 2011 recipient of the International Neural Network Society's Young Investigator of the Year Award. He received the University of Ulster's Distinguished Research Fellowship award in 2011. He coordinates the IEEE CIS Chapters activities and chairs the UKRI IEEE CIS Chapter. He is inaugural chair of the IEEE CIS BrainComputer Interface Task Force.

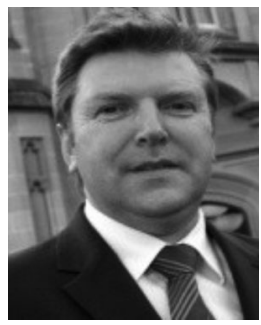

Liam P. Maguire received M.Eng. and Ph.D. degrees in electrical and electronic engineering from the Queen's University, Belfast, U.K., in 1988 and 1991, respectively.

$\mathrm{He}$ is currently the Head of the School of Computing and Intelligent Systems, University of Ulster, Derry, U.K, where he is also the leader of the Bioinspired Systems and Neuroengineering Research Team within the Intelligent Systems Research Centre. He has an established track record of securing research funding, approximately $£ 10 \mathrm{M}$, since his appointment and has also supervised 15 Ph.D. and 3 M.Phil. students to completion. He is the author of more than 200 research papers including 70 journal papers. His research interests include fundamental research in bioinspired intelligent systems (such as the development of computational effective spiking neural networks) and the application of existing intelligent techniques in different domains. 